\title{
"Walking with a Smile but Her Shoulders are Hanging Down" Exploring "Coloured" Women's Occupational Resistance in the Face of Personal, Historied and Societal Suffocation
}

\author{
*Chantal Christopher. B. OT (UDW), PG Dip in HIV/AIDS Clinical Management (UKZN), M.Phil. in Group \\ Therapy (UKZN). https://orcid.org/0000-0002-4959-7288 \\ Lecturer, Discipline of Occupational Therapy, School of Health Sciences, University of KwaZulu-Natal (Westville Campus), South Africa
}

\author{
Robin Wendy Joubert. Nat Dip OT (Pret), BA (UNISA), M.OT (UDW), D.Ed (UKZN). \\ https://orcid.org/0000-0002-7328-1590 \\ Hon. Associate Professor, Discipline of Occupational Therapy, School of Health Sciences, \\ University of KwaZulu-Natal (Westville Campus), South Africa.
}

\author{
Mershen Pillay. B.Sp. \& Hear. Th. (UDW), MSLP (UDW), D.Ed (UDW). \\ https://orcid.org/0000-000 I-8789-8439 \\ Hon. Associate Professor, Discipline of Audiology, School of Health Sciences University of KwaZulu Natal (Westville Campus), South \\ Africa. Speech and Language Therapy, Massey University, Auckland, New Zealand
}

Women in South African townships remain an invisible population in terms of understanding their lives and the implications on wellbeing. "Coloured" women's narratives problematise and critically explore their lived realities as socially constructed oppression that has not been addressed following the end of legislated apartheid. The politics of the personal, display the matrix of domination at play, in a specific sociocultural milieu while contrapuntally illustrating their standing up to resist capitulation. These actions and activities are occupations of resistance, occupations that are in opposition to, and possibly a reaction to, perceived injustice as well as the suppression of occupational choice and self-determinism. Occupations of resistance are hard work, performed with or without public acknowledgement while fostering perseverance to cope, to feel in control and, against the odds, to be resilient. The suffocating conditions that belie the narratives illustrate the lack of adequate solutions to these issues and call for a new humanism. These women's narratives allow us to envision authentic public health discourses that recognise grassroots explanations and solutions.

Keywords: Coloured women, occupations of resistance, new humanisms, women's suffocation.

\footnotetext{
"Our lives are Mobius strips, misery and wonder simultaneously. Our destinies are infinite, and infinitely recurring." 1:136
}

\section{INTRODUCTION}

South African townships* were created during apartheid with both spatial and social engineering goals to contain people of colour to peripheral urban areas with limited infrastructure ${ }^{a}$. Twenty-seven years post the dismantling of apartheid, women living in townships continue to live under suffocating conditions of poverty, unemployment, gender-based violence and socio-culturally informed values and roles ${ }^{2,3}$. This article aims to explore, in the vein of standpoint feminism, the non-essentialised, specific, lived experiences of "Coloured" women from a township, that displays at its core, transactional oppressions and everyday resistance ${ }^{4}$. It will allow us to understand the components of their daily struggles and the inherent occupations of resistance to these unmasked experiences of oppression. It is witnessed herein as 'standing up', a connotatively rich term coined from a co-researcher quote which alludes to both the literal facing up to hardship but also the figurative resistance imbued by the image. The focus is on "Coloured" women's life experiences, and attempts to illuminate their engagement in activities. The "Coloured" race label is an apartheid construction, created to describe people of mixed racial background. This remains a contested word, alongside the understanding that race is a social construct, the word is therefore placed within inverted commas, to disrupt the relaxed everyday usage and as a literary style marker to denote a term that is not used lightly but with discomfort.

The narratives unfold in a small South African township of Mariannridge, KwaZulu-Natal, wherein "Coloured" women live under constrained circumstances. Housing shortages, unemployment and poverty, substance usage and gender based violence form the backdrop to their lives. Their lives are far removed from the corridors of power and influence and do not reflect the shifting sands

aTownships promoted separation of the races, identification with only one's designated race classification i.e. in-group social identity, and division of the oppressed with spatial development that promoted easy state control of the people while offering different resources across the race hierarchy 
of the national debates around "Coloured" people, their place and belonging, their experiences or gender equality. During the period of this study, national debates regarding "Coloured" as a race label, their place within the so-called rainbow nation, the land debate and who were the rightful first nation people and thus owners of the land, were reignited and appeared across media sources. These debates although having reached the community, appeared to not change the material and ideational conditions amongst the people.

What perpetuates these sustained patterns of life? In answer to this question, women's voices are forefronted, disrupting objectivity politics within research, while documenting the women's contemporary socio-cultural subjectivities ${ }^{5}$. The research objectives that intersect herein are exploring "Coloured" identity and subjective influence on occupations with a view to developing local understandings that foster social illumination.

This article argues that the inherent conditions of living as a woman, within a township and further as a "Coloured" woman, has created specific material and socio-cultural conditions that are embodied within their everyday lives and occupations, and in their marginalised identities. The women's lives are nuanced by the continued participation in occupations and activities that were originally an external colonial conceptualisation of the subaltern figure that is gendered and racialised, now appropriated and enacted with different intention. "Coloured" women cannot and should not be seen as passive social constructs or be contextualised without this socio-cultural frame.

The voices and the experiences presented are deeply personal. The politics of the personal, are reflected in uncensored images that often cause disquiet and yet reveal the material conditions that create the petri-dish conditions from, and in which, life occurs. The personal as a discourse and explorative method, is crucial in social justice scholarship, as it disrupts assumptions, forefronts women, whose invisibility is then uncloaked- bringing them to the centre and creating cognitive dissonance. This alongside standpoint feminism and intersectionality serves as the framework for the representation, analysis and synthesis. The piece, aims to initiate discourses that will build transformative solutions within the occupational therapy profession that align with the rawness of these women's narratives, and simultaneously highlight the professions current limitations in our conceptualisation of our professional role in dismantling and speaking back to social injustices and neocolonial phenomena.

\section{METHOD}

This work stems from a critical ethnographic $\mathrm{PhD}$ study that created space within the Mariannridge community for women co-researchers to iteratively dialogue with their life experiences and build meaning and action alongside the researcher. The first author has worked within this area for eight years and, from 2016 to 2021, immersed herself in the area and culture by visiting and spending longer hours in the field, making field observations and notes, dialoguing and working with women, attending community meetings and events and reading relevant cultural artefacts in the public domain. The linkage to decolonial research allows for women to be seen as collaborators and not participants, who have power over their own narrative and what is revealed, as well as in dialogue with another women of colour with deep roots within the field through generational ties to "Coloured" identity and as a woman of colour.

"Coloured" women were invited to attend the dialogue sessions through advertising by the Community Based Organisation, Mariann Co-ordinating Committee, by word of mouth and by advertising on social media platforms. Altogether, seven women formally responded to the invite and were provided with written and verbal information regarding the study. They were required to complete informed consent forms and, by agreement, became the co-researchers who collaboratively explored their experiences and ideas. Many other women participated in meetings and group discussions that informed the reading and analysis of their lived experiences. Four co-researchers of the seven are presented within this article, see Table I below.

\section{Ethical considerations}

Full ethical approval was granted by the Humanities and Social Sciences Research Ethics Committee of the University of KwaZuluNatal, ethical review no: HSS/0544/0 I6D. A liberatory ethical paradigm was used, where the women who were to be approached as part of the research process were seen as co-researchers and not participants subject to research but as autonomous, independent thinkers with knowledge and inherent personal power. Women were taken through the intention of the research, the process and informed consent where they were able to choose to have a pseudonym or not, allowing the women choice. Although they chose to waive anonymity and thereby represent themselves, they are provided with pseudonyms for their safety and security within this local publication and have been summarily informed. They are presented below to provide further detail.

Table I: Co-researcher demographic information.

\begin{tabular}{|l|l|l|l|l|}
\hline Pseudonyms & Age & Employed & Children & $\begin{array}{l}\text { Resident of } \\
\text { Marian- } \\
\text { nridge }\end{array}$ \\
\hline Jackie & 55 & Yes & Yes & $\begin{array}{l}\text { Yes- long } \\
\text { term }\end{array}$ \\
\hline Leandra & 30 & Yes & No & $\begin{array}{l}\text { Yes- since } \\
\text { birth }\end{array}$ \\
\hline Colleen & 44 & $\begin{array}{l}\text { No } \\
\text { (informal) }\end{array}$ & $\begin{array}{l}\text { No, carer of } \\
\text { three nephews }\end{array}$ & $\begin{array}{l}\text { Yes- long } \\
\text { term }\end{array}$ \\
\hline Ruby & 44 & No & Yes & $\begin{array}{l}\text { Yes- since } \\
\text { childhood }\end{array}$ \\
\hline
\end{tabular}

\section{Data analysis}

Critical ethnography works with different sources of information to allow the themes to emerge that display a multi-layered reading of the experiences and discussions that were had at a community level. Data representation and analysis was informed by Saldaña and Omasta ${ }^{6}$, who provide guidelines on how to represent the multiple strands of information into a logical and coherent piece. These strands of information include the co-researchers' verbatim transcriptions of discussions, fieldnotes, information regarding the field context, and related information in the public domain called artefacts. Over and above this, as a result of intense immersion and understanding of the nuances of language and mutual rapport between the researcher and co-researcher, rich data emerged. Debriefing between the researcher and $\mathrm{PhD}$ supervisors, as well as female colleagues who self-label as "Coloured", as well as the iterative nature of the discussions with the co-researchers, allowed the themes and findings to be developed.

\section{Context}

Inspired by the need to separate the different race groups into 
their own separate and not equitable residential areas, the South African apartheid government of the day promulgated and upheld the Group Areas Act, of 1950. As a consequence, the township of Mariannridge west of Durban was built in 1976, for exclusive use by "Coloured" people relocated from disparate areas within the then province of Natal. The area lacked public transport, schools and other amenities, which made for difficult living. The municipal apartment blocks built originally with two bedrooms, have exhaustively hosted multiple generations of the same family, and remain overcrowded and unchanged since their inception. This is the area where we find our protagonists and their voices, living with vulnerability and given the opportunity, standing up to be the Mobius strips of misery and wonder that Joyce Carol Oates' refers to in the opening lines.

\section{FINDINGS/THE LIVED EXPERIENCES}

In keeping with critical ethnography, the findings cannot be read without context and a framed unpacking. This allows the women's voices to illuminate the occupational science reading that follows, simultaneously deepening the narrative and creating space for the reader to integrate the experiences. Their intersectional narratives lie on a bed of contextual life and sociocultural determinants, while the unpacking is offered as a sociological, cultural, political and psychoanalytical reading.

The findings cluster around the everyday occupations, which on further discussion and description illuminate both the mundaneness of gender oppression, as well as the occupations of everyday resistance. The themes move from gendered performativities in everyday practices, to fortitude in hard times, to love, power and abuse and enduring the heaviness of life through township panaceas.

\section{Everyday practices of subjugation: ritualising the per- formative}

Women's self-care has long been explored in decolonial literature through inherited colonial concepts of beauty and its representations that intersect with culture, race and identity. In South Africa, like other colonised countries, authors such as Erasmus ${ }^{7}$ have noted the subjugation of the person of colour through the recognition/ positioning of the coloniser as the epitome of beauty. Erasmus ${ }^{7: 381}$ evocatively stated this in:

"Western racisms in their various mutations make claims about the
body: about beauty and ugliness, and about sexuality. The politics
and violence of this racism operate in and through the body. This
legacy has meant that, in general, white bodies have been graced
with beauty while black bodies have been relegated to ugliness." In order to be perceived as appropriate and attractive, "Coloured" women have conceptualised beauty in particular ways, such as straightened hair, or having a light complexion, that persist into contemporary times. This is exemplified in Jackie's account.

"I know that for the most part of my life I never took photos. 'Cause, I didn't think I was pretty... I made a conscious decision to go to high school, where I thought that there'd be people with whom l'd fit in. So, everyone in my house was going to school in Sydenham, and I went to school in Wentworth because I thought that that's where the girls with kroes hair (tight curly hair) are, that's where the darker skin "Coloureds" are, that's where l'd be most comfortable."

Jackie reveals her disdain for her looks through her avoidance of photographs, and her attempt to fit in by journeying to a far-flung residential area (Wentworth) different from the one her family went to (Sydenham), in an attempt to belong. This self-disdain encapsulates the pressure that creates performative subjectivities of a teenager, in this case a darker "Coloured" child with kroes (tight curly hair) hair, who has already internalised straight hair and light skin as the epitome of beauty. It is these subjectivities that create self-imposed containment and separation, and simultaneously a sense of not belonging and belonging. The knock-on effect on occupational choice and engagement is seen within the anecdote as uncomfortable choices that support belonging and self-comfort.

This teenager angst, although long since passed, shadows the present forty years later within anecdotes that belie Jackie's pain. As an adult woman with status as a community leader and an activist, Jackie ironically recounts being invisible versus becoming visible to "Coloured" men ( previously her school mates), through doing economically well and the chemical metamorphosis that hair relaxers can bring.

"I always think about that when I see all the guys. You know, who we were at school with. And they're like "Oh, hey howzit?" And you think, gee when we were at school you didn't even give me a second look (laughs). I said that once to one of the guys. He was so shocked. He said: "Jen you think about that?" Of course, I think about it. I think about it all of the time. And now you look at me driving a car and all of a sudden, I'm like oh... "How come I missed you?" (laughs). You don't think that we can create Revlon relaxers and we can help ourselves (laughs)." (Jackie)

In counterpoint to this, are the everyday practices of "performing their bodies" 8 that demonstrates imposed occupations ${ }^{9}$ from the generational line of women that came before. This ritualises the performative and facilitates feelings of belonging and becoming. The becoming is read here, both through the embodiment of society's beauty prescription as well as becoming like the well-received vision of what "Coloured" women should look like.

"Maybe it was also watching my mother and her sisters, getting up on a Saturday morning and washing their hair and then ironing that hair. You know you could hear the hair burn (laughs)." (Jackie)

The finer nuances of ritualised performative feminine beauty regimens is displayed through Jackie's witnessing of family members beautifying themselves by washing and straightening their hair and the alluded-to suffering for the end-product (burning of the hair). This is but one level of analysis, and also intersects with "Black" subjectivities as a construct of pervasive colonial mores.

The length of time and effort required to make hair presentable necessitated that hair was done on Saturdays, which allowed females to present themselves at functions on Saturday night, and at Church on Sunday, looking their best. This is poignantly displayed in the quote below, rich in the tradition of hair, family time and good times, the aunts would prepare to go out to dance.

"Even we wash our hair, once a week. And then we had to sit down between my aunty's legs and plaited these big huge terrible plaits and they would sit there, they'd get ready to go to the dance..." (Jackie)

The production of these gendered performativities is pervasive through other activities of daily living and appears to be part of the 
very fabric of women's lives. Leandra speaks about different fitting in and belonging through the following suit of community-wide behaviours, which fosters collective performativities. The example presented is a community-wide phenomenon of women presenting themselves within the area, outside of their homes, with pyjamas, bedroom slippers and doeks (headscarves) at any time of the day.

\section{"They want other people to see them in a certain light and because the next woman is walking in the street in her pyjamas at this time they feel it's okay so I can also do it, to fit it. They wanna fit in". (Leandra)}

Converse to belonging and becoming through the associated fitting in, other girls and women feel the isolation that not 'fitting in' causes. Colleen speaks of being alone since her childhood primary school days.

\section{"I had this class that just used to, Ai, they used to tease me, call} me names and all that..."(Colleen)

Bullying, name-calling, excluding others or feeling pressure to conform or fit it in, or follow traditions and rituals, are practices of subjugation and are particularly relevant to women's social construction under particular conditions. The anecdotes and discussion, although framed within everyday life and routines of self-care/presentation, specifically related to beauty and outward appearances, are endowed with psychoanalytical meaning. Through the process of becoming and belonging, choosing invisibility or visibility, or self-imposed containment versus separation, individual and collective performatives intersect with life's patterns and one's behaviours. They are both enacted and sub-conscious and create personal meaning. These anecdotes produce a gendered and racialised narrative that for these "Coloured" women continues to be created under particular geospatial and socio-cultural conditions. Identity/identities are formed through these complex processes, with resultant conceptualisations of oneself not always within one's conscious control.

These conditions occur alongside, intersecting with and often a harbinger of other Hard Times.

\section{Hard Times have made us who we are: the making of marginalised identities}

Hardships dominate the lives of the working class, through a multiplicity of living conditions and experiences. The subsequent unfolding of experiences from "Coloured" women, display intersectional issues ranging from health to being disenfranchised, which makes for difficult living, reflecting both hardships and survival.

"But a "Coloured" woman... I won't lie, there's so much you can carry. But there's a lot that we can't take. We pretend that we can take things, at least for me I know I do that" (Ruby)

Health is a "state of complete physical, mental and social well-being and not merely the absence of disease or infirmity" $10: 1$. When this definition is applied to the lives of women in South African townships, from impoverished neighbourhoods and limited social capital, it appears utopian and difficult to attain. Ruby, above, speaks of pretending to cope while carrying a heavy load, alluding to mental health strain but simultaneously centres fortitude. The experience below, focuses on this lack of personal health attention while 'just trying to cope'.
"Post-school I also neglected my body, neglected my health. I think it's ill health that has forced me to... because even now it's my diabetes, my high blood pressure, that forces me to throw away what I was eating, but otherwise, I don't think I would have bothered... To eat healthy, to do all the right things and half of the time we just trying to be here we just trying to cope." (Jackie)

Contrapuntally alongside this demonstrated coping, is the physical and emotional work that goes into making a life through "exerting" oneself, resulting in little residual energy being left.

"If we say it's exercising it's about pushing yourself etcetera. Maybe women don't really need that push though. They got everything, so in the one area they exert them self. I'm exerting myself every day. I also think some of those things are so called class (related). When women are struggling and they trying to put food on the table and they unhappy, you can't..." (Jackie)

Difficult times for women resonate with patriarchy, wherein social mores predicate the power of men, whether they be husbands, lovers, sons or brothers. The following extracts represent the layers of inherent power that are prevalent in these women's lives, from an aging mother caring for her young son while "rendering in the useless body", to being reminded you are homeless in your own home through male ownership. Finally, it is seen within women's perception and care of themselves through a mirror of patriarchal love relationships.

"Even my mother can't see, she's got my brother under her arm and my brother is basically her husband. She cooks, she cleans she washes you know. When he walks through the door she does everything. If we took my brother away from that, my mother would have absolutely nothing to do. And in the meantime, she's just rendering in the useless body, useless body so Ja...the drama of "Coloured" woman (laughs)". Jackie.

"Any time... any given time and I was always the bad one even though I wasn't you know. I was getting abused hit... but the thing is with him, even today, his mother passed away last year September, she's gonna be a year dead now... and even the house that we in, I am reminded it's not your house!" (Ruby)

"I always see women's care for themselves related to being in a relationship. If you see a woman who's in a relationship, she's happy she's in love, somebody's lady. Once she's not there, or she's in a long-term relationship then she's just here again. Who cares, let me walk around with a stocking on (stocking on the head to straighten hair), all kinds of things but obviously it's class related, it's an expensive lifestyle," (Jackie)

A person's occupations are often associated with class or sociocultural structures. Imposed occupations are perpetuated through the norms and values that are found in societies and adopted by marginalised people? ${ }^{9}$. In Cloete and Ramagondo's study, alcohol usage by "Coloured" women in the Cape Winelands of South Africa was explored, who historically received wine in payment for work done. At a cursory glance, this theorisation appears to display similarities to the historical anecdote below. In the local example below, cigarettes were used as partial remuneration. 
"When you are 18 and you left school then the Greek cafés employed these "Coloured" girls and she says that they were introduced for instance to cigarettes as part of their (pay). So, every day you left the café going home, and you were given a packet of cigarettes and she says, 'so we just smoked these cigarettes, I mean we had a packet a day and we had enough cigarettes to smoke on the hour you know". (Jackie retelling an anecdote she had recently heard from an 80-year-old oral historian)

The concept of imposed occupations, however, has a negative connotation, that of the occupation being imposed on a passive subaltern group of people, whose lives are subsequently arrested by the imposed nature of the occupation. In this example, it is read as being exploitative, a cheap tactic by employers, to appear benevolent while fuelling tobacco addiction and paying in kind, versus wages, during that particular era. There is a victorious tone in having cigarettes to smoke on the hour, and portrays something other than passivity and imposed occupation (albeit capitalistic expolitation). Instead, perhaps it is akin to non-sanctioned occupations" as adopted by marginalised identities (the women), where the smoking is part of a resistant response to being subaltern within a society ${ }^{12}$.. It was perceived as being liberated, modern, edgy and progressive to be a smoker and a "Coloured" woman at that time.

\section{Love, power and abuse: negotiating relationships through alternate meaning making}

Adult hetero-sexual love is often epistemically violent in patriarchal societies and perhaps more so in marginalised communities such as the "Coloured" women of Mariannridge. This theme connects with patriarchy and the inexplicable life choices and occupational engagement of marginalised identities ${ }^{12}$. This is demonstrated in the following accounts, illustrating the need for different types of love, for status, surviving abuse and women making meaning from and within aberrational love relationships.

To make herself visible, and break from a strict religious family background Ruby acquired status through becoming a gangster's girlfriend.

"I ran away from home to look for company in someone else. Love, that I never got from anyone. So, for him because he was this dancer, he was this gangster type, so wherever he walks no one would do anything to you, so I felt safe with him. I lived with him, it must have been 6 or 8 months everything was cool. And then the abuse started happening. I started feeling scared. I couldn't go back home and say, 'this is what's going', on so I used to hide.... He never worked, I used to get up and go work for Janelle and Jordan (her children)." (Ruby)

When Ruby speaks of abuse, she means physical and mental abuse, that can be delivered in many guises, such as lack of support and distancing from co-parenting, to infidelity and exploitation of women for monetary gain. The pain of having love not reciprocated, infidelity and abuse delivered instead, is alluded to below.

“He don't support me, he don't give me nothing. He jols (parties) with these Black girls and then comes and demand for money by me... Yeah I'm scared of AIDS mam, I'm scared." (Colleen)

While unable to be supportive, Colleen's husband reprimands her for being supportive of her biological family, in this case orphaned nephews who reside with her. She is thus held to a higher standard while being made to choose a family side.

"Ja, and my husband blames them (her nephews) and says Ja, I'm too much for my family, so I must stay with my family. 'Cos I choose them but he's the one that's cheating." (Colleen)

The story of unrequited love seen in the example above, as well as a lack of romance and life being wholly dissimilar to images fed to young girls regarding appropriate behaviour of men, leads to unfulfilled lives. The pain of these experiences is evidenced within Ruby's examples.

"You know all my life, he's never bought me a ring. I bought my own ring when we got married. I think it was like two months after I was so angry, I took it off and I threw it away and never bothered and up until today I still don't have a ring." (Ruby)

“'“Coloured" men don't know how (to treat a woman), not all, l've seen guys treat their women, you know nice. Buy them flowers and whatever. And then you sit there and you envy, and it makes you have other thoughts, and think that god, this man only wants sex from me. Or am I just here because he knows I can cook, I can clean, I can do everything else l've raised his children." (Ruby)

The ring is a symbol of marriage and commitment and the torment of having to buy her own ring, and then refusing to wear it, brings home the harsh reality and paradox of being with someone and yet being partnerless. The social and economic burden is lain at Ruby's feet, and her need for love and care goes unanswered.

Women's participation in these relationships is seen from another angle when Jackie observes that women stop caring about how they look when they are in a long-term relationship. This predicates self-care on being attractive to men during the initial phases.

“I need to look good 'cos I'm in a relationship... I always see women's care for themselves related to being in a relationship. If you see $a$ woman who's in a relationship, she's happy, she's in love, somebody's lady. Once she's not there or she's in a long-term relationship then she's just here again. Who cares let me walk around with a stocking on all kinds of things..." (Jackie)

The stocking above refers to a cut off section of a pantyhose that is then knotted at one end, and worn over one's hair as a snug cap, to keep straightened hair in shape.

\section{The Heaviness of Life: standing as amelioration}

The narratives presented within this article are often heavy, filled with difficulties and struggle and are made poignant by Ruby's explanation of the situation on a Friday night in a home.

"Maybe if your child's gonna go home today, it's Friday night somebody's drinking, somebody's fighting, your morale everything just gets dropped. And you think why should I even try? There's nothing more that I can do for myself..." (Ruby)

In opposition to the suffocation and heaviness of life, women displayed resistance to life's oppressions. Standing up, or standing, is a resistant stance to stooping under life's weight. This is Jackie's image of herself and her daughter, strong women standing against dominant narratives and doing the "hard work". 
"It takes a little bit of standing and I think that's what makes us women, like myself and my daughter. And you get up one day, and you say, 'this is not going to be my role in life'. But that doesn't make it easy; it makes it harder because it would have been easier for me to sit around the flat. I said No! Actually, I'm going to give my daughter what I didn't have, but then that took a lot from me, that's hard work, getting up...its hard, it's hard work". (Jackie)

Standing up to, and being resistant to the lived daily oppressions differs for different women. Other women walk with a smile although weighed down, while eking out a life with "whatever" money and resources they have, perhaps easing the pain through drinking over the weekend. This is a vivid image which gives the article its title, as it reveals paradoxical strength yet vulnerability.

"I think it's the area where you live. I think it's the people's mentality. It's like here, if you look at all of us, Roxy walking with a smile but her shoulders are hanging down. Can you see? She looks tired but she knows when she goes back up, there are certain things she needs to do, get this and that, with whatever. But then you start drinking for the weekend and we think that's life because you so used to it. I think "Coloureds" are scared for change." (Ruby)

Township economics, patriarchal capitalism as tradition and selfsacrifice form the backdrop of women's lives as a constant fight for money. The anecdotes below display a South African history of far-flung poorly resourced townships away from central business areas and places of employment. This fosters feelings of marginalisation and exclusion from the forces of production. Losing assets such as money saved (second anecdote) is often a loss that cannot be mediated by time, as it may push a person into a zone of living from hand to mouth with no safety net.

'But our life experience if you think to yourself oh $\$ \$ \# k$ man, you can't even make it to go and buy yourself a panty somewhere. You just working for food and that's just all that "Coloureds" can do. But outside areas you look at them and think 'God their mothers got such nice jobs; how did this happen to us?' Or was it the place that you were just dumped?' (Colleen)

"I'm supporting these children, they smoke whoonga (highly addictive drug), they steal from me... They steal me blind, I tell you, I got a lock on my room door, on my bedroom door ... now when I was in hospital in May, they... drew my money out of the bank." (Colleen)

Finally, old stereotypes of what "Coloured" women should look and sound like is seen as the continued racialisation of people by other people of colour. Colleen feels the brunt of being a dark complexioned "Coloured" with 'kroes' hair that is profiled by other South Africans as a Black African. She becomes one of the many who believe that during apartheid times, they were not White enough and now post- apartheid are not Black enough ${ }^{13}$.

"I'm telling you, they say that there 'she got kroes hair and black, blacker than me and she can't talk Zulu'... Serious, even when you go to the police station, how many times l've had problems here at our local police station, going to report my nephews and all that and they say that there...'(Colleen)

The above anecdote refers to Colleen being made to feel less than, by the local police when she attempts to report her drug taking nephews at the police station. The power of the local law enforcement, the authorities, is utilised to belittle, disregard and other Colleen, by expecting her to be able to converse in the local language of isiZulu as a result of racial profiling. This is in contrast with the perception that police are in positions to assist and of accessibility and openness to women.

\section{Township Panaceas: escape comes in different forms}

The lure of alcohol as a panacea for life is easy to understand. In the litany of an endless list of work to do, first at work and then at home, alcohol use then appears to be an escape for Ruby. Here it is important to see the discourse from a South African perspective that Ruby felt, that it was not seemly as a "Coloured" woman to appear at the White employers' house smelling of alcohol, a reference to stereotypes around "Coloured" women and the old apartheid hierarchy of White people being superior. Further this is a feminist act, to recognise that men are held to a lower behavioural standard. This is a layered narrative of racialised and gendered subjectivities creating the context for patterns of behaviour that then fuel behaviour and non-sanctioned occupations.

“...'cos I was getting tired. There was so much getting put onto me, physical things ... Now when I come home to children I must still stand and cook, get things done, washing. The next day I'm back again, and maybe even sometimes I'll have a drink. I say I'm going to the clinic, but it was catching up with me slowly cos I was going through some stuff you know?" Ruby

"I thought no, I can't go there smelling of alcohol and whatever, and it's a White woman ... what they gonna say about me because l'm a "Coloured"... I got to a place where one day I said, 'even this is not working'. And my husband's in every other shebeen (local informal tavern), sitting and drinking. God, he can't even buy bread, he's not worried about nothing'. I started slowly going on the cider and eventually back to beer which is the cheapest. And my child, he even said 'Ma you looking so nice what happened?' I said, 'boy you won't understand until the day you experience your own problems'. He said. 'Mum but you should be able to handle, you've handled so much already'. I mean I come from suicide, two attempted rapes, two and they don't know all that you know." (Ruby)

Escape can come in different forms, and is not always through drugs or alcohol. The dark side of bearing the weight of abuse, life and the endless hurt that it brings, is suicidal ideation and suicide attempts to escape from the existential pain.

"At the time I fell pregnant with Jade. I was alone, he was never around. Go sleep out weekends, come back with love bites and when I would approach him he would hit me. And then I was 8 months pregnant with Jade, I couldn't take it anymore... I said Lord I'm not gonna bring a child into a world where there's no unity, even in this home. I'm empty. There's just nothing I feel anymore. Anyway, I slit my wrists. He walked in that day, God can strike me dead if I'm lying. I was sitting on a little chair, he still booted me off that chair and said l'm causing bad luck in his mother's home." (Ruby) "I really wanna get out of that household of mine. Sometimes I think ai, let me take my own life..." (Colleen)

\section{SYNTHESIS}

Contemporary South Africa necessitates a new urgent imperative, one that will generate new ways of living; new humanisms. These 
new humanisms are required to meet marginalised identities such as the women in this study, whose lives do not resonate with contemporary grand narratives of wellness, personal agency, resilience and being recipients of therapy at a population/community level. Without these new humanisms, occupational therapists may read the narratives and find these women dehumanised or less than, or in need of direction and professional guidance, all professional reasoning that naively compares the women's narratives to the world as it is (or perceived to be), or the neoliberal system. This therefore entails looking at the insidious and covert mechanisms through which current oppressions exist, supporting Gramsci's ${ }^{14}$, contention that social injustice does not require overt forces to exist. This article fosters this new humanism by bearing witness to women's voices, which generates critical conscientisation of the matrix of domination ${ }^{15}$ in operation within their lives. The matrix of domination is everywhere in place and space, and this critical conscientisation augments the discourses on African feminisms, particularly within the profession of occupational therapy.

The oppression supports and drives patriarchal traditions, and perpetuates women's subjugation that results in contemporary ghettoization of the mind, body and spirit. This is on display in the in text sentences, that display both the standing up and the subjugation, for example "I'll have a drink", "that's just all that "Coloureds" can do", "And you think why should I even try?", "It takes a little bit of standing and I think that's what makes us women". Within this particular township - conditions have changed but not materially, continuing as the legacy of apartheid, which resonates with women from similar circumstances across the racial spectrum. What is important to note is the particular cultural milieu present, in these women's lives - "Coloured" women from KwaZulu-Natal. While essentialised and stereotyped constructs may present "Coloured" people as homogenous, these women are distinct and dissimilar from other South African "Coloureds". Still, their occupational engagement and patterns of life resonate with the work of Erasmus ${ }^{16}$, Cloete and Ramugondo" and Galvaan 17 on life as a "Coloured" woman within the Western and Eastern Cape of South Africa.

"Coloured" identity is dynamic, and although it was not made overt in this piece, it is the backdrop; a prism through which life is read. Personal identity is a construct that one usually adopts at a point in one's life, however South African racialisation and the legacy of apartheid make this a contested issue. Identities were imposed (through apartheid legislation and its machinations), and continue past apartheid's legislative end. Identities are inherited through socio-cultural traditions and formed under specific geopolitical pressure-cooker conditions. The politics of identity cross complex contemporary self-labelling issues, politics of location, socio-cultural patterns, occupational engagement and in particular, women's understanding of their lives.

Everyday practices of subjugation, is an indictment on colonised depictions of what beauty is, made worse by apartheid policies such as the pencil test ${ }^{18}$. This test utilised a pencil stuck into hair and the ease at which it fell out, to determine the straightness of the hair as a marker of race classification. Hair and its straightness were directly linked to being able to transition to Whiteness through reclassification of your race, which afforded state-sponsored privilege. The perpetuation of these practices (relaxing of hair), is linked to old race reclassification and then identification with being White, misogyny and fulfilling gender stereotypes of what women should look like. This phenomenon is seemingly misplaced in contemporary times. However, it underscores the number of gendered, racialised performativities at play, for example preferring light complexions. In a paradoxical illustration of this, "Coloured" women who have gone on to win the Miss South Africa beauty pageant, had straight hair (non-relaxed hair), in a country that is currently celebrating the win of Zozibini Tunzi as Miss Universe, as a dark woman, with natural short African hair ${ }^{19}$. Time has changed/diversified body representations, however not for all women.

Wicomb ${ }^{20}$ writing about shame and identity amongst "Coloureds" speaks of the body as "metaphorical text", as a "site of shame" and "bound up in the politics of location". Although twenty-three years have passed since Wicomb's ${ }^{20: 94}$ statement, this study vindicates her provocative declaration that "different groups created by the old system do not participate equally in the category of post-coloniality". Desiree Lewis ${ }^{21: 205}$, a South African feminist dissects this contemporary colonial inscription of Black bodies in her statement: "Black bodies are marked according to racial and gendered inferiority- carry dense cultural meaning and how African female bodies became sites for others' inscription". The body in this piece, is the text through self-inscription, through racialisation, misogyny and the beauty economy inspiring particular inscription, through cultural underpinnings and tradition. The body wears pajama's into the street, has internalised hair and skin colour in racialised ways and walks with a smile, but with her shoulders hanging down. The body, the woman, becomes the text, owing to the need for social belonging and the sustained creation and perpetuation of marginalised, internalised and imagined identities.

"Hardships have made us who we are," is a theme that intersects with marginalised identities which find meaning and belonging through occupations of resistance ${ }^{\prime \prime}$ and the counter-narrative of fortitude and strength embedded consistently throughout the narratives. The narratives, although heavy and often painful to bear witness to, demonstrates individual insight, personal and sporadic agency, a passion for life and abiding hope, that conditions will change. These are paradoxically subaltern figures of socio-cultural and historical times and conversely, also not the subaltern characters that are silent and non-existent, as seen in the narratives. This is the nature of the women's suffocation; it is a smothering of the change process by socio-political, historical, racial, cultural and gendered forces, however it is not the extinguishment of life energy and spirit.

The theme Love, Power and Abuse exposes the stark reality of gender-based violence against women in this particular neighbourhood. Although not unique to this area ${ }^{b}$, these women's voices display an unsatisfactory relationship between women and men, not only as romantic partners, but between fathers and daughters, pastors and women parishioners, and unequal power relationships. Patriarchy as an ideology and a driver of oppression ${ }^{22}$, through traditional representations of women, portrays women as requiring protection and men as the benefactor, de facto family leader. In this critical ethnographic study, however, it can be further explained as a legacy of colonialism and apartheid that serves to reframe the issue somewhat and decentre it from a wholly racialised and gendered perspective ${ }^{23}$.

The Heaviness of Life references the unchanging morass and suffocation of life within this township. It begins unveiling itself, within

${ }^{b}$ Gender-based violence is endemic to South Africa with Government statistics noting $26 \%$ of women have been abused by intimate partners http://www.statssa.gov.za/?p=14559 
the opening quote: “...your morale everything just gets dropped. And you think why should I even try? There's nothing more that I can do for myself". The quote displays the battle-fatigue that conditions of life have wrought on an individual. It cannot be separated from the other themes and represents a forcefield that keeps one in place and promotes a dysthymic collective view of oneself. This is juxtaposed with anecdotes of standing up, standing to face up to the heaviness that would otherwise leave one bowed. If occupations are those activities that give meaning to life ${ }^{24}$ then standing up is an occupation, and particularly an occupation of resistance. Occupations of resistance are the seemingly small acts of wearing pajamas all day and into the streets, to bold acts of going to the shebeen to find one's partner, or confronting the police's essentialising of "Coloured" appearence. Occupations of resistance as postulated here, are occupations that are in opposition to and possibly a reaction to perceived injustice, but also the suppression of sanctioned occupational choice and self-determinism. Occupations of resistance may therefore support non-sanctioned occupations, as well as be outlying to society's values and codes. These occupations are hard work as they are performed with or without public acknowledgement or approval, and yet serve to allow one to persist and endure, to cope, feel in control, and against the odds to the demonstrate fortitude within the narratives.

Township Panaceas demonstrate that distractions and moodaltering substances are a balm for existential pain. It allows for a woman to ensure that the "next day I'm back again" or contrarily, to envision a time when one is free, "let me take my own life". Inherited patterns, inherited pain, imposed occupations perhaps conspire with the prevailing stereotypes and the highly contextualised occupational engagement to limit occupational choice ${ }^{17}$ and occupational possibilities ${ }^{25}$. Generations of women are repeating cyclical "undesirable and immoral" occupations as seen from the cultural context or non-sanctioned occupations. This appears to set them further on the margins of a marginalised community.

Pat Collins'15 imagery of a matrix of domination, is an apt symbol for this condition, as it figuratively encapsulates the enmeshment of issues versus the imagery of intersectionality. Each woman experiences individual suffocation, albeit while resisting and "standing up". The matrix of domination will not collapse or break from educational, motivational, or typical therapeutic attempts to facilitate a new life journey. These public health efforts aimed at improving quality of life, are part of the building of comfortable, complacent narratives, part of the machinery that drives "walking with a smile but her shoulders are hanging down". It is part of the status quo maintaining the matrix, the patriarchy and an underclass of women that are the resilient workhorses, pruning squares to fit into round holes or outliers into playing their part within the rainbow nation squad. In Reflecting Rogue: inside the mind of a feminist, Pumla $\mathrm{Gqola}^{26}$ presents the case that well-meaning women prune other women to prevent the perceived string of vulnerabilities that may await them. The narrative indicates that women have become a mechanism for patriarchy and oppression, from bullying others to a mother's enmeshed relationship with her son, and allowing abuse and parasuicide in her home.

While the Truth and Reconciliation Committee held in South Africa, and its related work on restorative justice, attempted to bring closure and healing to the country's population, its failures require a reconciliation of the devastation that colonialism and nonhumanistic politics have wrought on people of colour and in particular, upon women of colour. From old-style women's magazines of light-skinned straight-haired models to new versions of yellow bone (colloquial slang for light-skinned) television presenters, women are fed a recipe of aspirations, how to look, how to be the good wife, how to be the "smile but her shoulders are hanging down", how to cope and keep standing, and how to fit in. They are fed a diet of what to do, how to be, become and belong, and failing that, to become and belong to sub-cultures and marginalised identities. Rita Barnard 27:347 in her work on Contesting Beauty writes: "it is in the fertile loam of the marginal that we may find the structures of power revealed in peculiarly fascinating ways". This reveals a disconnect from formulaic occupational therapy prescriptions/ interventions that utilise concepts of women's resilience and selfempowerment and that through effort, hard work and application women may find their way out of the ghetto.

\section{CONCLUSION}

This study demonstrated the intersectional layers of particular historied, societal, gendered and personal oppression, while representing the women of this community through their voices and their subjectivities. Women appear to exist complicitly within these conditions, although wise to their suffocation. It is macabre suffocation with one's eyes wide open. As a result, they offer up occupations of resistance to mitigate against the suffocation, often skirting or being subjected to societies censure. Occupations of resistance allow occupational therapists to work with contested life and occupational choices as they offer a different framework through which to engage with women. Occupations of resistance are part of an intersectional and decolonial understanding of transformative critical occupational therapy. These occupations of resistance are strength based as they illustrate women's occupations that work to ameliorate the injustices of life, establishing a niche of belonging in personal and collective enactment and the embodying of a fighting spirit that is alternately standing up to normative expectations, but also finding strength and succour in performative activities.

The suffocating conditions that belie the narratives problematises the lack of adequate solutions to these issues and calls for new humanisms within the profession and beyond. These women's narratives allow us to envision authentic public health discourses that recognise grassroots explanations. Fortitude, although present needs to be read as in reaction to the conditions of life and an enduring, not as empowered practices that forefront their health or themselves. We find in their names, their uncomfortable self-disclosures, their unfettered, uncensored language and life experiences everything but the subaltern character of history and our (professional) imagination. We find painful truths, regarding "Coloured" women's lives and our failure as occupational therapists to address meaningfully and with catalytic action, women's suffocation with viable and real solutions as we, continue to work within frameworks that covertly and overtly perpetuate the system. All our lives are Mobius strips, the purveyor and the purveyed.

We relive the past in rituals of revival,

Unravelling memories in slow time; gathering the present (Busia ${ }^{26: 203}$ )

\section{ACKNOWLEDGMENTS}

The co-researchers on this venture are acknowledged as the keepers of the knowledge as they gave of themselves through their participation, so we could better understand.

\section{AUTHOR CONTRIBUTIONS}

Chantal Juanita Christopher is the primary researcher and the au- 
thor of this paper including the conceptualisation of the data. Robin Wendy Joubert and Mershen Pillay as supervisors of this research assisted with editing, analysis and expertise in data representation.

\section{DECLARATION OF CONFLICT OF INTEREST}

The authors reported no potential conflict of interest financial or otherwise.

\section{FUNDING}

This work was supported by the National Research Foundation under Grant I I0892; University of KwaZulu-Natal, College of Health Sciences and UCDP.

\section{REFERENCES}

I. Oates JC. The Corn Maiden and Other Nightmares. New York: Mysterious Press;20II.

2. Miraftab F. Contradictions in the Gender-Poverty Nexus: Reflections on the Privatisation of Social Reproduction and Urban Informality in South African Townships. In: The International Handbook of Gender and Poverty: Concepts, Research and Policy. S. Chant, Editor. Edward Elgar Publishers; 2010: 644-648.

3. Jurgens U, Donaldson R, Rule S, Bahr J. Townships in South African cities - Literature review and research perspectives. Habitat International. 20I3; 39: 256-260.

https://doi.org/10.1016/j.habitatint.2012.10.01 I

4. Harding S. Rethinking Standpoint Epistemology: What is "strong objectivity?". The Centennial Review. 1992; 36(3); 437-470.

5. Hooks B. YEARNING: race, gender and cultural politics. Boston: South End Press; 1990.

6. Saldaña J, Omasta, M. Qualitative Research: Analyzing Life. Thousand Oaks: Sage Publications; 2016.

7. Erasmus Z. Hair Politics. In Senses of Culture: South African Culture Studies. S Nuttal, C Michael, Editors. Cape Town, Southern Africa: Oxford University Press; 2000:38I

8. Hauge M. Bodily Practices and discourses of hetero-femininity: girls' constitution of subjectivities in their social transition between childhood and adolescence. Gender and Education. 2009; 21 (3): 293-307. https://doi.org// 0.1080/09540250802667625

9. Cloete L, Ramugondo E. “I drink”: Mothers' alcohol consumption as both individualised and imposed occupation. South African Journal of Occupational Therapy. 2015; 45(I). https://doi.org/10.17159/2310-3833/2015/v45nola6

10. World Health Organisation. The First ten years of the World Health Organization. 1958. [accessed 2019 March]. https://apps.who.int/iris/handle/I0665/37089

II. Kiepek NC, Beagan B, Laliberte Rudman D, Phelan S. Silences around occupations framed as unhealthy, illegal, and deviant. Journal of Occupational Science. 2018; 26(3): 34I-35.

https://doi.org/10.1080/14427591.2018.1499123

12. Christopher C, Joubert RW, Pillay M. Marginalised Coloured identity: performative expression in post-apartheid South Africa. Manuscript submitted for publication. 2022.

13. Adhikari M. Not White Enough, Not Black Enough: Racial Identity in the South African Coloured Community. First edition. Athens: Ohio Press; 2005.

14. Gramsci A. Selections from the prison notebooks of Antonio Gramsci. Q Hoare, G Nowell-Smith Editors. London, United Kingdom: The Electric Book Company; 197I.

15. Collins P. Black feminist thought: knowledge, consciousness, and the Politics of Empowerment. 2nd ed. New York/London: Routledge; 2000.
16. Erasmus Z. 'Oe!My Hare Gaan Huistoe':Hair-Styling as Black Cultural Practice. Agenda: Empowering Women for Gender Equity. 1997; 13(32): II-16. https://doi.org//0.2307/4066/47

17. Galvaan, R. Occupational Choice: The significance of socio-economic and political factors. In: Occupational Science: Society, Inclusion and Participation.GE Whiteford, C Hocking, Editors. New Jersey: Blackwell; 20I2: 152.

18. Oyedemi T. Beauty as violence: 'beautiful' hair and the cultural violence of identity erasure. Social Identities. 2016; 22 (5): 537-553. doi: https://doi.org/10.1080/13504630.2016.1157465

19. British Broadcasting Corporation. Miss Universe 2019: 'May every little girl see their faces reflected in mine'. [accessed 2020 February I7]. https://www.bbc.com/news/newsbeat-507| 2666

20. Wicomb Z. Shame and identity: the case of the coloured in South Africa. In: Writing South Africa: Literature, apartheid and democracy, 1970-1995. D Attridge, R Jolly, Editors. Cambridge: Cambridge University Press; 1998: 91-107.

21. Lewis D. Representing African Sexualities. In: African Sexualities. S. Tamale, Editor. Oxford, UK: Pambazuka Press; 201 I:199-216.

22. Courville $C$. Re-examining patriarchy as a mode of production: The case of Zimbabwe. In: Theorizing Black Feminisms- the visionary pragmatism of black women. SM James, AP Busia, Editors. London: Routledge; 1993:31

23. Arvin M, Tuck E, Morrill A. Decolonizing Feminism: Challenging Connections between Settler Colonialism and Heteropatriarchy. Feminist Formations. 2013; 25(I): 8-34. Retrieved from www.jstor.org/stable/43860665.

24. WFOT. (2018, May). Definitions of Occupational Therapy from Member Organisations. Retrieved May 05, 2020, from WFOTWorld Federation of Occupational Therapy: https://www.wfot.org/about/about-occupational-therapy

25. Aldrich RM, Dickie VA. "It's hard to plan your day when you have no money": Discouraged workers' occupational possibilities and the need to reconceptualize routine. A Journal of Prevention, Assessment and Rehabilitation. 2013; 45(I): 5-I5. https://doi.org/I0.3233/WOR-131596

26. Gqola PD. Reflecting Rogue: inside the mind of a feminist. Johannesburg, South Africa: Jacana Media; 2017.

27. Barnard R. Contesting beauty. In: Senses of Culture. S Nuttal, C Michael, Editors. Cape Town, Southern Africa: Oxford University Press; 2000: 344-362

28. Busia AP. Performance, Transcription and the Languages of the SelfInterrogating identity as a "post-colonial" poet. In S. M. James, \& A. P. Busia (Eds.), Theorizing Black Feminisms- the visionary pragmatism of black women (p. 203 London: Routledge 1993: 203.

Corresponding Author

*Chantal Christopher

Email: christopherc@ukzn.ac.za 